\title{
Correction to: Are non-accidental regularities a cosmic coincidence? Revisiting a central threat to Humean laws
}

\author{
Aldo Filomeno ${ }^{1}$ \\ Published online: 18 February 2020 \\ (c) Springer Nature B.V. 2020

\section{Correction to: Synthese} \\ https://doi.org/10.1007/s11229-019-02397-1
}

The funding information in the article was not complete. Please find here the full information.

Funding This work was supported by the Instituto de Investigaciones Filosóficas (Universidad Nacional Autónoma de México) through a fellowship from the postdoctoral fellowship program DGAPA-UNAM, and by the grant 'Formal Epistemology - the Future Synthesis', in the framework of the program Praemium Academicum realized at the Institute of Philosophy of the Czech Academy of Sciences.

Publisher's Note Springer Nature remains neutral with regard to jurisdictional claims in published maps and institutional affiliations.

The original article can be found online at https://doi.org/10.1007/s11229-019-02397-1.

$\triangle$ Aldo Filomeno

aldo.filomeno@pucv.cl

1 Instituto de Filosofía, Pontificia Universidad Católica de Valparaíso, Valparaiso, Chile 